\title{
Acciones para la salvaguardia del Cinema América en Trastevere (Roma). ${ }^{1}$ Actions taken for the \\ Mampaso, C. (2014). Acciones Para la salvaguardia del Cinema América en Trastevere (Roma), Designia, 3(1), 58-73. safeguard of Cinema America In Trastevere (Rome).
}

\section{Resumen:}

\section{Palabras clave:}

Patrimonio, movimiento social, autogestión, legislación cultural.

\section{Key words:}

Heritage, social movement, self-management, cultural legislation.

Recibido: 15-ago- 2014 Aceptado: 2-dic- 2014

\footnotetext{
*Arquitecta de la Universidad Politécnica de Madrid (ETSAM). Magíster en Restauración del Patrimonio de la Scuola di Specializzazione in Beni Architettonici e del Paesagsio de la Universidad de la Sapienza (Roma, Italia). cmampaso@gmail.com
}

\footnotetext{
1 Artículo inscrito en la línea temática Experiencias en gestión y protección del patrimonio cultural. Sus contenidos se derivan, por una parte, de una tesis de investigación de fin de máster, y de otro lado, de la posterior puesta en práctica profesional de dicho trabajo
}

Este trabajo, dedicado a las salas cinematográficas del siglo $X X$, tiene como fin ilustrar la relevancia histórica, tecnológica y arquitectónica que dichos espacios supusieron para el patrimonio moderno y cultural de Roma. Como caso de estudio fue seleccionado el Cinema América, construido por el arquitecto Angelo di Castro en 1954, por ser hoy en día el único que conserva íntegros todos los atributos arquitectónicos y espaciales de esa nueva tipología. Abandonado en el 2000 y ante la amenaza de demolición, fue ocupado en noviembre del 2012 por un grupo de estudiantes universitarios con el apoyo de la comunidad, con el fin de preservar la actividad cultural en su interior y restituir este importante foco cultural al barrio donde se encuentra. El proyecto para su salvaguarda se desarrolló en dos fases, una académica y otra de acción social y administrativa. Entre las acciones tomadas la más importante fue la preparación del documento para su inclusión en el listado de Bienes de Interés Cultural del Ministerio Italiano de Cultura. Finalmente, tras su desalojo pacífico por las fuerzas del orden, el 28 de noviembre del 2014 fue incluido en la lista del Patrimonio Cultural de dicho Ministerio (Decreto Ley 139-2014, Roma) bajo una doble protección (histórica y artística), con lo cual se estableció un precedente para la salvaguarda del patrimonio moderno de la ciudad.

\section{Abstract}

Referred to the 20th century's cinemas, this study aims to illustrate the historical, technological and architectural significance of such venues for Rome's cultural heritage. The case study selected is Cinema America, which was built by architect Angelo di Castro in 1954 and remains as the unique cinema that keeps intact all the architectural and spatial attributes of its typology. It was abandoned in 2000 and threatened from demolition, which leaded to its occupation in November 2012 by university students supported by the community, as a way to maintain its cultural activity and to restore it for the neighbourhood. The project for its safekeeping was developed in two phases: academic research and social-legal actions. Working out the nomination for the cultural centre's inclusion into the Italian Ministry of Culture's official list of cultural assets was the most significant action, among others undertaken. Following a peaceable building eviction by police in November 28th 2014, it was finally included into the list with both an artistic and historical protection, thereby setting a precedent for safeguarding the city's modern heritage. 
La realidad recurrente de la especulación inmobiliaria en los centros urbanos salpica nuestras ciudades casi sin darnos cuenta. De un día para otro aparecen solares vacíos o fachadas colgando de andamios, sin estructura en su interior. Alli surgen, en su mayoría, edificios anónimos que siguen una lógica de estilo contemporáneo, poco relacionada con el contexto urbano e histórico. Estos nuevos edificios, por lo general, no se destinan a compensar las necesidades básicas de la ciudad o del barrio, sino que al ser promovidos por intereses privados se convierten en viviendas de lujo, hoteles o centros comerciales de marcas internacionales. Las antiguas construcciones, en su gran mayoría pertenecientes al periodo comprendido entre finales del siglo $X I X$ y los años setenta del $X X$, se ven así afectadas, principalmente, por los motivos expuestos por Jokilehto (2003): falta de reconocimiento social y de las instituciones; falta de protección de las normativas urbanísticas y de patrimonio; y obsolescencia funcional, energética y material de sus tipologías.

El Cinema América, construido en 1954 por el Arquitecto Angelo di Castro, es único en su tipología y en sus atributos arquitectónicos en toda Roma, sin embargo, fue abandonado en el año 2000 y estuvo amenazado de demolición. En su solar, la sociedad Inmobiliaria Progetto UNO Srl preveía construir 40 miniapartamentos de lujo, en una ciudad donde hay 245.000 viviendas vacías. 
Afortunadamente, coyunturas políticas, sociales y culturales permitieron recuperar la esperanza en las instituciones públicas y paralizaron el proyecto de demolición. Pero sobre todo, llevaron a establecer un antecedente en materia de herramientas administrativas, legislativas y sociales que ponen al arte y a la arquitectura del siglo XX a la cabeza de la salvaguardia del patrimonio de la ciudad.

Entre las acciones emprendidas se desarrolló un proyecto cuya metodología se dividió en dos fases: una académica, centrada en el análisis histórico y tipológico del inmueble, el cual incluyó el análisis comparativo, el diagnóstico del estado de conservación y la propuesta de restauración; la otra fase, de acción social, abarcó un proceso de socialización con la comunidad y las instituciones, orientado a incluir el inmueble en la lista del patrimonio moderno de Roma y evitar así su demolición.

\section{CONTEXTO HISTÓRICO Y URBANO}

Cronología de los acontecimientos

El Cinema América se encuentra en la calle Natale del Grande, entre la Plaza de San Cosimato y la calle Francesco Rippa (figura 1), eje vertebral de Trastevere desde la época medieval. La primera representación cartográfica del solar donde se ubica la sala apareció en 1891 en las plantas de Roma del Instituto Cartográfico Italiano, cuando la Calle Natale del Grande se abría paso entre las huertas del Convento de San Cosimato para configurar un nuevo eje urbano en su momento.
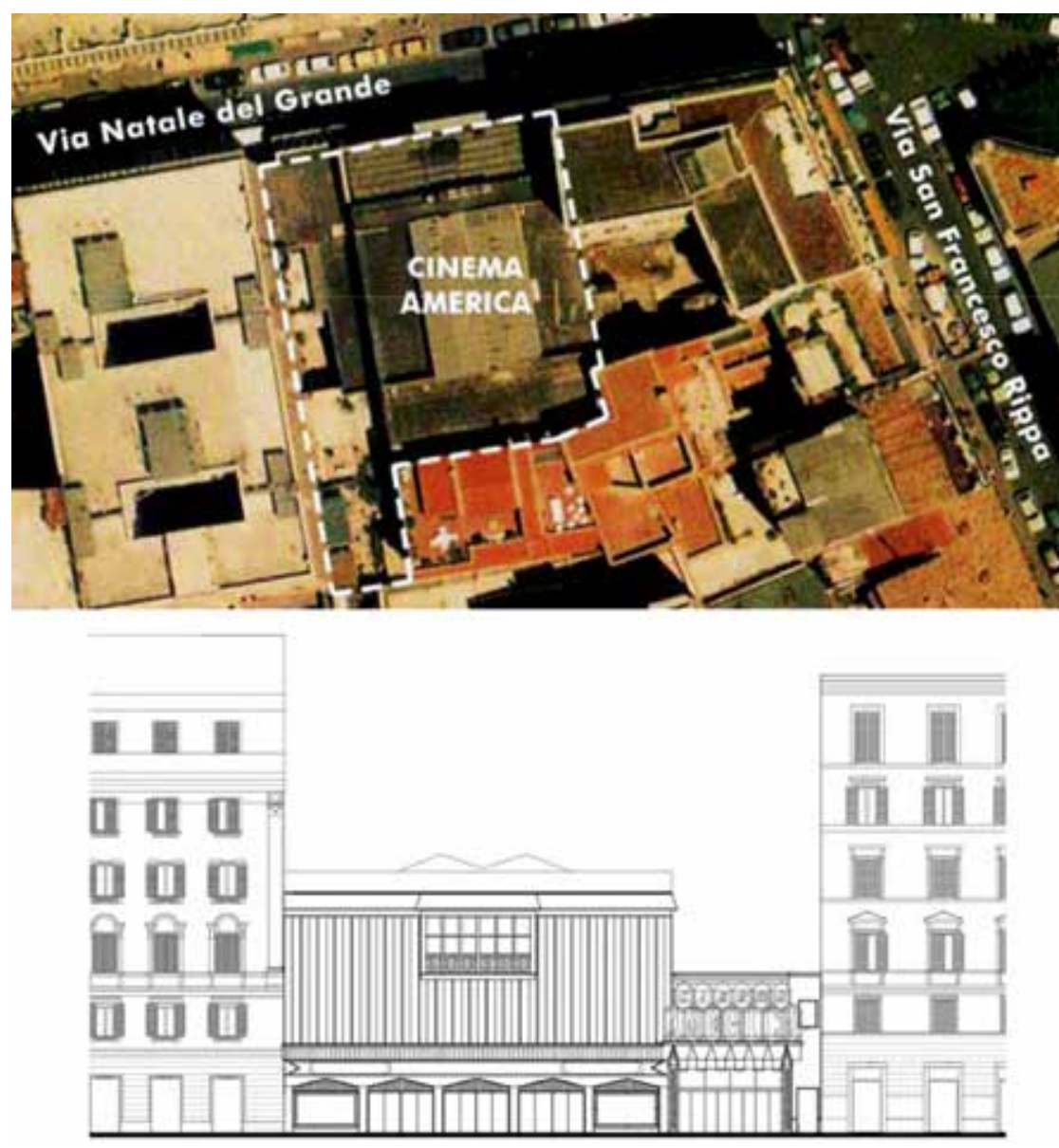

Figura 1. Localización del Cinema América (alzado general) Fuente: Arq. Cristina Mampaso Cerrillos 
Hoy en día el Cinema ocupa dos parcelas catastrales, una larga y estrecha que penetra en la manzana y otra rectangular que permaneció sin edificar hasta la construcción del Cinema Teatro La Marmora en 1923. Según fuentes históricas (entre ellas las del Archivio Storico (apitolino), en ese año el Señor Icilio Amizoni, propietario del solar, presentó un proyecto para construir una sala de proyecciones. La Marmora se terminó en 1927 después de largas disputas con los habitantes del barrio, quienes reclamaban más viviendas y menos espectáculos. Aunque fue un lugar de referencia para el teatro de variedades de la escena romana, tuvo una vida corta. En 1954 se demolió junto con la parcela adyacente para erigir el Cinema América, el cual debía seguir los estándares constructivos definidos por la nueva normativa de 1951 para edificios de público espectáculo del Ayuntamiento romano.

El proyecto, encargado al arquitecto romano Angelo di Castro junto al Ingeniero Francesco Serventi, se inauguró en 1956 y se convirtió en la sala con la pantalla panorámica y el techo retráctil más grandes de Roma. El cine permaneció activo hasta el año 2000 cuando la crisis de la industria cinematográfica obligó a cerrar la mayoría de las salas de la ciudad por los altos costos de adaptación a los nuevos formatos (Intrieri, 2004). En 2004 la Sociedad Progetto UNO Srl compró la propiedad y

${ }^{2}$ Archivio Storico Capitolino - ASC

(1923). Costruzione di un cinematografo. Prot. 15080 / Via Natale del Grande. Progetto di ampliamente. Acceso en marzo de 2013. presentó un proyecto de demolición y posterior construcción de 40 apartamentos, idea rechazada en 2008 tras una gran oposición de los vecinos. En 2012, ante la amenaza de un nuevo plan para 20 apartamentos presentado por la sociedad, el América fue ocupado pacíficamente por un colectivo de estudiantes universitarios con el apoyo de la comunidad y del vecindario (figura 2). 

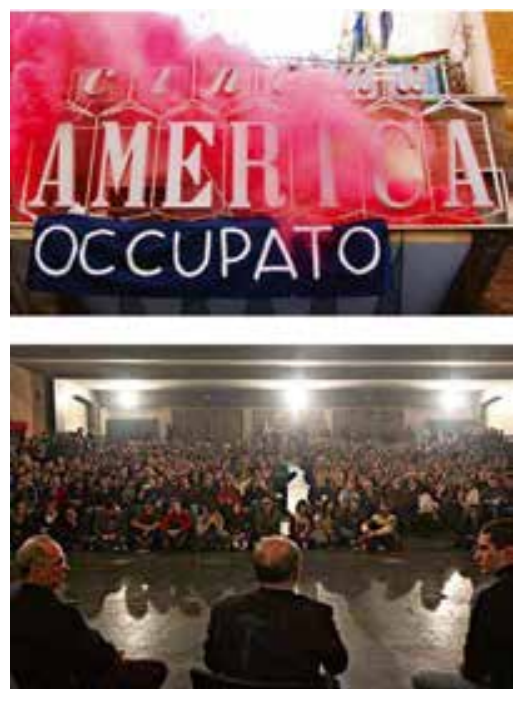

Figura 2. Momento de la ocupación y asamblea pública. Fuente: Comitato per il Cinema America.
Desde entonces y hasta la actualidad, el Cinema ha revivido su actividad y su función cultural con y para la gente del barrio de Trastevere al ofrecer una intensa programación mensual de conciertos, ciclos de cine y teatro. Así, se ha convertido en una referencia cultural de la ciudad junto a otros espacios "ocupados" como el Teatro Valle y el Cinema Palazzo.

Nacimiento y decadencia de una nueva tipología: el cinematógrafo en Italia La nueva tipología arquitectónica que nació a finales de 1800 en Francia junto a la invención de la película, llegó a Roma a principios del siglo XX con la construcción en 1904 del Cinema Moderno, primera sala cinematográfica de la capital. Cabe también resaltar que en pleno auge de las vanguardias en Italia, personajes como Giacomo Balla, Marinetti y Arnaldo Ginna firmaron en 1916 el Manifiesto del Cine Futurista, cuyos atributos artísticos y formales se verían reflejados a lo largo del siglo XX en el diseño arquitectónico (Intrieri, 2004).

En 1915 el arquitecto Marcelo Piacentini realizó en la Plaza de San Lorenzo in Lucina el Cinema Corso, obra que abrió por primera vez el debate en defensa de la contemporaneidad y sus consecuencias, como el uso de materiales modernos o el nacimiento de tipologías adaptadas a las nuevas exigencias tecnológicas. En un artículo publicado en 1918 en la revista Architettura Italiana, Piacentini destacó la necesidad de deshacerse de una inspiración disonante con su tiempo, que lo ponía en un estado de inferioridad en relación con los siglos precedentes. Por eso resaltaba que el teatro había sido construido libremente y respondía a una nueva sensibilidad. Con determinación e ingenio estructural, el arquitecto sentó las bases de una nueva tipología derivada de las salas teatrales, caracterizada por pocos pero significativos elementos de diseño:

- La marquesina de hormigón en la fachada con pliegues geométricos que encuadra la entrada. 
- Las tipografías luminosas en neón que aluden al espectáculo como un hito nocturno en las ciudades.

- El techo retráctil de la sala para ventilar el humo y refrescar durante el verano.

- El uso del hormigón en soluciones estructurales que permiten cubrir grandes luces, así como la utilización de nuevos materiales, entre ellos el linóleum y las siliconas.

- La búsqueda formal y material de una mejor acústica, como también de la exaltación sensorial de los cinco sentidos.

- La simbiosis del diseño arquitectónico con el arte contemporáneo, presente en el interior gracias a una colaboración interdisciplinar entre artistas y escultores.
En la construcción del Cinema América, el arquitecto di Castro (formado en el estudio de Piacentini) reflejó cada uno de estos elementos, característicos de esa nueva tipología (figura 3). Así, optimizó el espacio y la estructura de manera ejemplar y convirtió al lugar en la única sala monofuncional que reunía todas esas condiciones tipológicas.

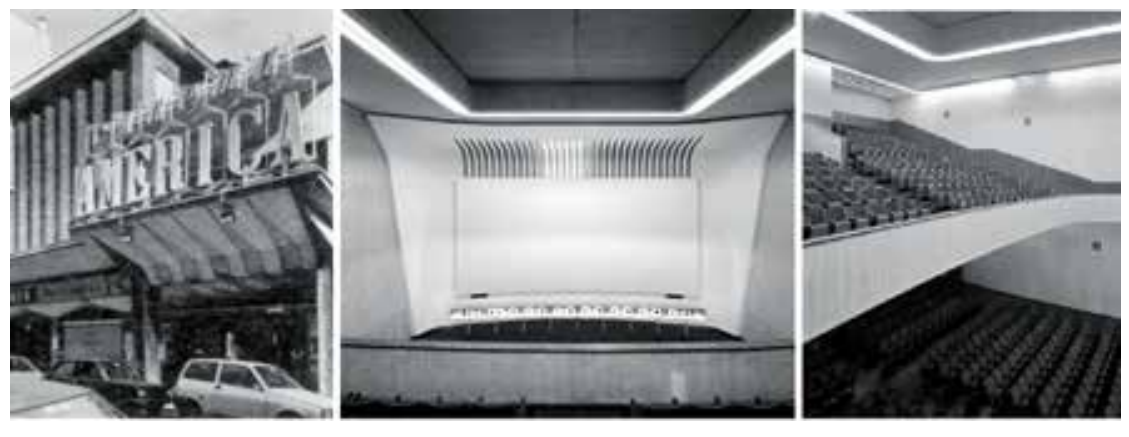

Figura 3. El Cinema América en los años noventa Fuente: Fotografía de Fabrizio Fioravanti

Sin embargo, la realidad actual es que de aproximadamente 120 salas (alrededor de 300 fueron construidas en aquellos años), el 13\% han sido reconvertidas en teatros, el 23\% están abandonadas y en muy mal estado de conservación, el 26\% se han transformado en tiendas o salas de juego y el $32 \%$ siguen funcionando pero con el formato de multisalas (figura 4).

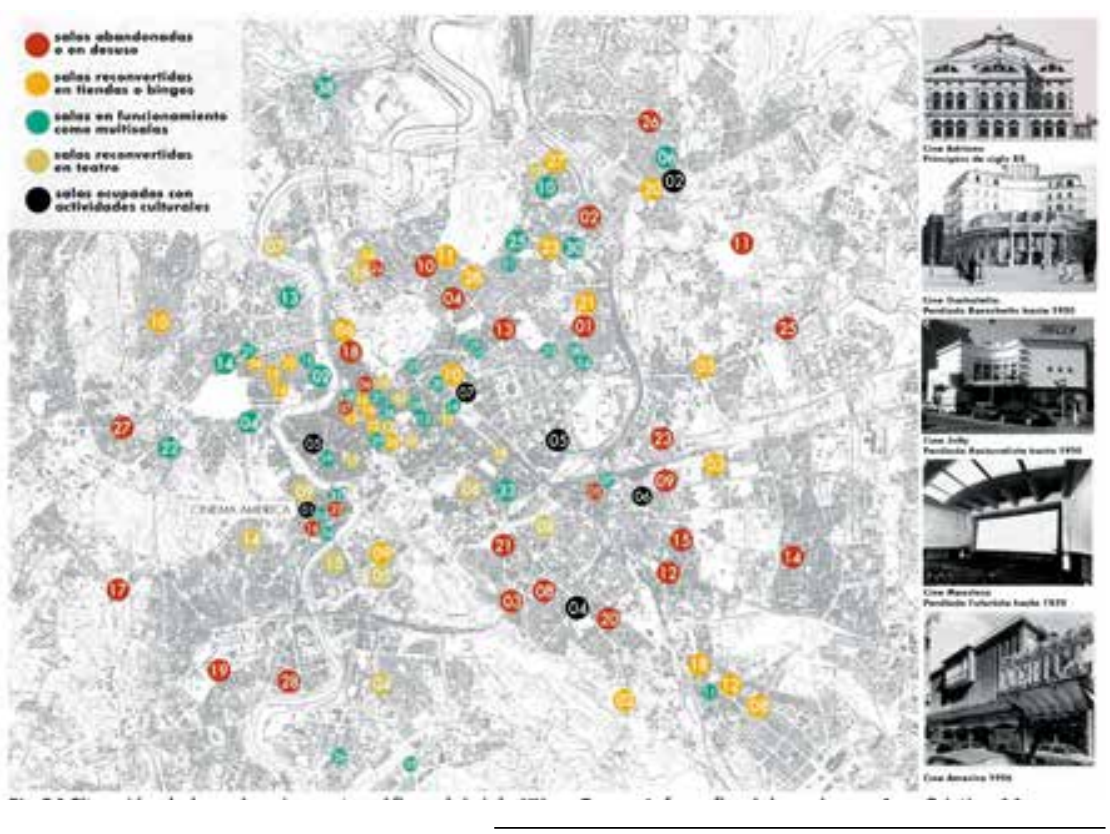

Figura 4. Las salas cinematográficas del siglo XX en Roma Fuente: la autora 
Cabe recordar que para el tiempo del surgimiento del Cinema América y a lo largo de los años cincuenta y sesenta se produjo en Italia un boom de la industria cinematográfica. Cinecittà, un estudio fundado en 1937 por Benito Mussolini con el eslogan "La Cinematografía es el arma más fuerte", llevó a Roma a convertirse en la segunda capital del mundo del cine, precedida solo por Hollywood.

\section{MARCO LEGAL EN ITALIA}

El artículo 9 de la Constitución Italiana que entró en vigor en 1948 afirma: "La República tutela el paisaje y el patrimonio histórico artístico de la Nación". Sin embargo, hasta 1974 el patrimonio estaba tutelado por el Ministerio de Instrucción Pública, según la ley Bottai de 1939. En 1974 se creó el Ministerio de Cultura que mediante el Decreto ley 490 de 1999 logró unificar la legislación en materia patrimonial en el llamado "Testo Unico". No obstante, este no hacía mención a las distintas expresiones del patrimonio contemporáneo. Solo hasta 2004, año de aprobación del Decreto Legislativo 42 o Ley del Patrimonio Cultural, la arquitectura contemporánea fue nominada por primera vez en una ley nacional de protección.

\section{Ámbito regional: Plan General de Roma del 2008}

Antes de la aprobación del Plan General de Roma (PRG) en 2008, la manzana del Cinema América estaba catalogada como zona $A$, lo cual incluía edificios de interés histórico, arquitectónico y monumental. Fue posible parar el primer proyecto de la Sociedad Progetto UNO gracias a la deliberación nro. 661 del 2005 del Ayuntamiento de Roma, que tutelaba los locales de interés cultural y establecía una superficie máxima alterada del 50\% y un mínimo del $20 \%$ del espacio para servicios públicos. Pero un nuevo riesgo surgió cuando la Sociedad presentó otro proyecto de 20 miniapartamentos y tres plantas de parqueaderos.

Uno de los documentos innovadores del PRG es la "Carta de la Calidad", destinada a catalogar y proteger las trazas, los conjuntos urbanos y edificios de la arquitectura moderna. Aun así, la única sala cinematográfica romana que aparece catalogada es el Cinema Airone del Arquitecto Adalberto Libera, construido en los años treinta y en completo estado de abandono y degradación.

Hay que remitirse al plano de usos del suelo del PRG para ver identificado el solar del Cinema América como Tejido Urbano T3, lo cual significa que pertenece a un desarrollo urbano de los siglos XIX y XX. Al estudiar en detalle la normativa, al interior del Tejido T3 está consentida la intervención DR1, es decir, se permite la demolición con reconstrucción de los edificios erigidos después del Plan General de 1883, carentes de valor arquitectónico y que hayan alterado con volúmenes adicionales y sustituciones la tipología y el trazado de la ciudad. 
Además de poseer un altísimo valor arquitectónico, la construcción del América no ha alterado el trazado urbano, pues ese solar ha sido siempre del cine. Ahora, en aras de profundizar en el concepto de valor arquitectónico y usarlo en favor de la declaratoria de Bien de Interés Cultural, hace falta pasar a la normativa nacional ${ }^{3}$.

Ámbito Nacional. Ley del Patrimonio Histórico Nacional nro. 42 de 2004 En el artículo 10 de esta Ley, los bienes culturales son descritos como bienes muebles o inmuebles pertenecientes al Estado, las regiones y los gobiernos locales, al igual que entidades públicas y privadas sin ánimo de lucro con un valor artístico, histórico, arqueológico o etnoantropológico. Si bien el América es una propiedad privada con fines claramente lucrativos, al leer con más detalle el apartado del mismo artículo se especifica que la categoría también puede cobijar aquellos bienes pertenecientes a cualquiera, con particular importancia por su relevancia política, militar, literaria, científica, artística y cultural, representantes de la identidad y la historia del país. Al mencionarse la palabra "cualquiera" se incluye la propiedad privada. Además, se nombran los conceptos de identidad histórica y cultural.

En el artículo 11, apartado e, aparecen por primera vez como obras de especial interés cultural aquellas de arquitectura contemporánea con valor artístico. A su vez, el artículo 12 habla exclusivamente del proceso de reconocimiento de dicho valor y específica que deben estar sujetos a tal proceso los bienes muebles o inmuebles de autor no viviente realizados hace más de 50 años. Esa valoración, de resultar positiva, se transformaría en la declaratoria de Bien de Interés Cultural. En consecuencia, ya sea en el ámbito regional o nacional, todo se limita en esencia a demostrar el valor arquitectónico y artístico del edificio.

${ }^{3}$ La sigla BIC para hacer referencia a los Bienes de Interés Cultural es propia del contexto colombiano. En Italia son más usados conceptos como bienes culturales o tutela del patrimonio
En el caso del América, ya han transcurrido 60 años desde su construcción y su arquitecto falleció en 1989. Por ende, el reconocimiento debió haberse iniciado automáticamente de no ser porque en 2011 se aprobó el Decreto Legislativo 70 que modificó la edad de reconocimiento del valor artístico de un inmueble de 50 a 70 años desde el momento de su construcción. Esta deliberación, además de 
ser muy ambigua en el campo de la propiedad privada, ha eliminado la posibilidad de catalogación de toda la arquitectura de la segunda mitad del siglo $X X$.

El artículo 113, referente a la propiedad privada, especifica que el reconocimiento del valor artístico de un bien privado debe iniciarlo el propietario o la administración pública, lo cual dejaba dos opciones para realizar la solicitud: a través de una sociedad con figura jurídica (por ejemplo DOCOMOMO Italia), o por medio de una institución como el Ayuntamiento de Roma o la Región Lazio. Finalmente se optó por la segunda alternativa, dada la repercusión política y social que suponía el compromiso de estas instituciones.

\section{ACCIONES CONTRA LA}

\section{DEMOLICIÓN}

Fase de información pública y de propuesta de restauración

Durante una Asamblea realizada el 17 de febrero de 2014 (figura 5) con el respaldo de representantes del mundo de la cultura, el cine y la arquitectura, así como de DOCOMOMO Italia, se presentaron a la comunidad los estudios y las propuestas de restauración y revalorización de la estructura. El proyecto dio a entender cómo a través de la documentación histórica y el análisis del estado existente es posible plantear una opción viable contra la demolición, la cual podría convertirse en un modelo de salvaguarda para este tipo de edificios del 1900 en Italia.
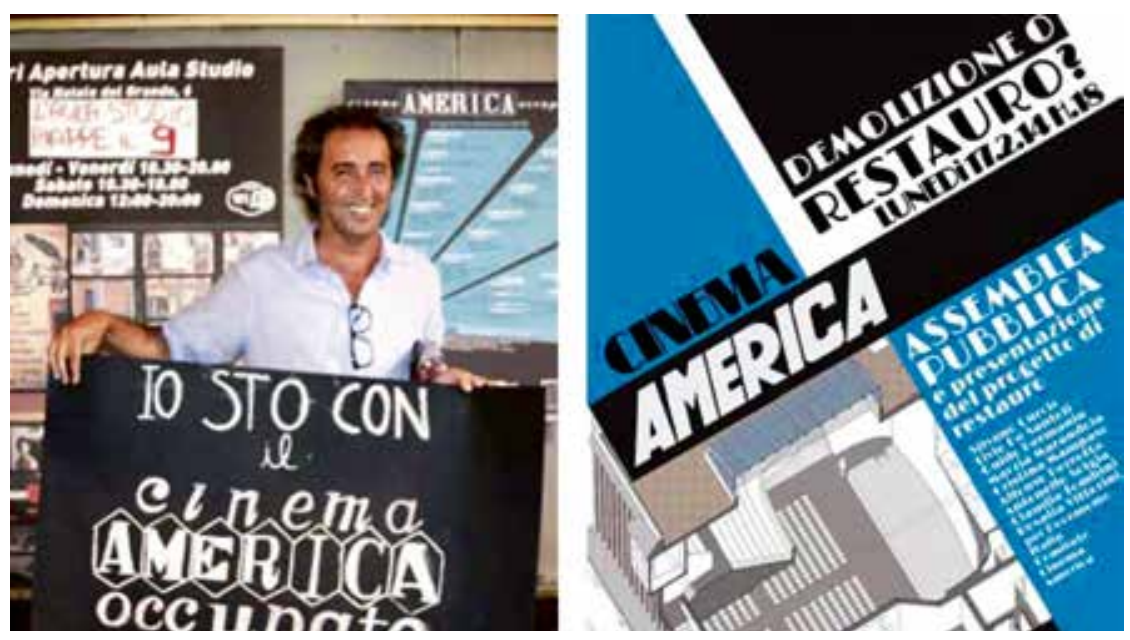

Figura 5. Acciones contra la demolición Fuente: Comitato per il Cinema America (fotografía), Jaime Rojas (infografía)

El estudio se articuló en tres fases:

- Análisis histórico del contexto urbano, cultural y socioeconómico del barrio de Trastevere en relación con el Cinema América y con sus etapas de construcción y desarrollo, desde la demolición del Cinema-Teatro La Marmora hasta el presente. - Análisis comparativo con el resto de las salas cinematográficas del mismo periodo, con el fin de identificar los atributos tipológicos y el valor arquitectónico del inmueble. - Análisis y conocimiento de la obra, complementado con un levantamiento arqui- 
tectónico efectuado de forma directa e indirecta con estación total, junto a un examen del grado de conservación de los materiales en el interior y en la fachada.

- Diagnóstico del estado de conservación de la estructura, mediante el cual se identificaron los sistemas constructivos y materiales usados, al tiempo que se valoró su capacidad de adaptación a nuevas normativas y de respuesta a nuevos usos.

- Fase de proyecto, que evaluó si el edificio cumplía la normativa vigente contra incendios en términos espaciales, morfológicos, acústicos y materiales (figura 6).

A su vez, se propusieron posibles

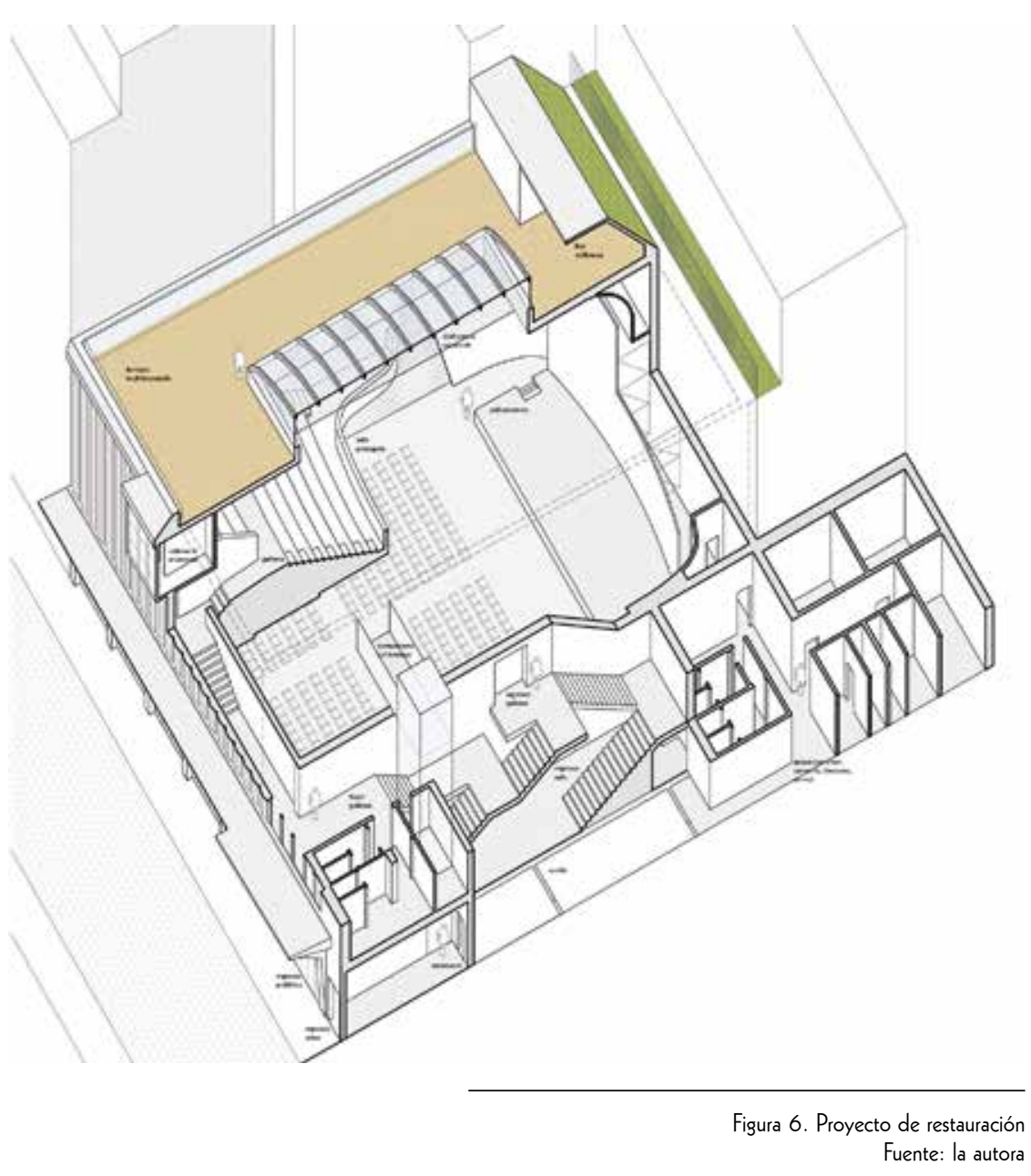

intervenciones que permitirían diversificar el uso de la sala, tales como:

- Adaptación de la pantalla a las dimensiones actuales.

- Creación de un pequeño escenario para representaciones teatrales y de un acceso secundario (directamente de la calle a los camerinos) para actores y artistas.

- Recuperación de las luminarias y del efecto de luz indirecta en los pliegues de los falsos techos diseñados intencionadamente por el arquitecto.

- Uso de la cubierta como espacio de agregación y reconexión del interior de la sala con el exterior a través de una cúpula traslúcida que sustituiría el techo retráctil, pues por normativa acústica este sería inviable. 
Una conclusión importante de este estudio fue destacar que la sala se ajustaba espacialmente a la Norma Técnica 261 de 1996 emitida por el Ministerio del Interior, referente a la prevención contra incendios en locales de público espectáculo. Este hecho limita el alcance de la intervención, excepto en los aspectos técnicos de las instalaciones, el tratamiento de las superficies internas y externas sin grandes modificaciones en la estructura y la morfología del lugar.

En la asamblea de febrero de 2014 se compartió la idea del Cinema América no solo como un ejemplo de la lucha por el derecho a la cultura contra la especulación inmobiliaria, sino también como un exponente único de la tipología "cine", revestido de altísimo valor arquitectónico y social.

\section{Preparación del dossier de}

candidatura a Bien de Interés Cultural

Dentro del Ministerio de Cultura existe la Dirección General para la Protección del Paisaje, el Arte y la Arquitectura Contemporánea (PaBAAC) que desde el 2002 desarrolla una iniciativa para el reconocimiento, la catalogación y la salvaguarda de las obras con un interés artístico relevante de la segunda mitad del siglo XX.

Son dos las modalidades a través de las cuales se puede solicitar el reconocimiento de una obra: para el patrimonio mueble, por medio de la Ley de Derecho de Autor $633 / 41$, en tanto que para el patrimonio inmueble se cuenta con la declaratoria de Bien de Interés Cultural, según la Ley del Patrimonio Histórico Cultural. De acuerdo con la $\mathrm{PaBAAC}$, los requisitos mínimos para que una obra sea reconocida son:

1. Haber sido citada en al menos un estudio histórico sobre la arquitectura contemporánea nacional.

2. Haber sido publicada en al menos dos estudios históricos sobre la arquitectura contemporánea regional.

3. Haber sido presentada en al menos dos revistas de arquitectura en el país.

4. Tener una reconocida importancia dentro del panorama de la arquitectura nacional (o al menos regional) de los años en que fue construida.

5. Poseer un carácter sobresaliente en la evolución de la tipología que representa y presentar un proceso innovador de carácter distributivo y funcional.

6. Introducir y experimentar de forma significativa con nuevos materiales y con nuevas tecnologías constructivas.

7. Haber sido proyectada por una figura reconocida del panorama arquitectónico local, nacional o internacional.

8. Representar un valor añadido en el contexto urbano donde se encuentra. 
Como se ha especificado, al tratarse de un edificio de propiedad privada, la solicitud de protección del Cinema debía proceder del propietario o de la administración pública, según lo establecido en el artículo 113 de la Ley del Patrimonio. Pero más allá de los requisitos enunciados, la PaBAAC no brinda una información clara sobre la documentación que un privado o un representante público tendrían que entregar al Ministerio de Cultura. Aun así, junto con la arquitecta Claudia Tombini y profesionales del sector, se elaboró un dossier con los documentos requeridos para valorar el edificio, de manera que se dio una respuesta científica y sólida a los ocho puntos citados. Este documento comprendía una descripción general del edificio, un análisis histórico y de la obra de Angelo di Castro ${ }^{4}$, registros fotográficos y catastrales y el levantamiento arquitectónico. Se incluyeron más de 5000 firmas y cartas de apoyo de personajes e instituciones relevantes del mundo de la arquitectura y la cultura, tales como Giovanni Carbonara, DOCOMOMO Italia y el Colegio de Arquitectos de Roma. El texto fue presentado al Ayuntamiento de Roma y a la Región Lazio, quienes después de varias reuniones aceptaron remitirlo en nuestro nombre al Ministerio de Cultura, tras reconocer el valor del América como modelo de iniciativa social y de salvaguarda del patrimonio moderno. Igualmente, la acción fue respaldada por los principales medios de comunicación nacional e internacional en todos los formatos de divulgación.

${ }^{4}$ Para tal fin se accedió a varias fuentes, en especial al Fondo Archivio Di Castro Angelo, 1910-1989, ubicado en el Archivio Centrale dello Stato, Soprintendenza archivistica del Lazio (acceso en 2013).

\section{RESULTADOS Y CONCLUSIONES}

El mayor logro obtenido ha sido conseguir unir al Ayuntamiento, a la Región y al mundo de la cultura con un discurso coherente. Se han dado soluciones a problemas específicos y se reavivó el debate entre las instituciones acerca de la vulnerabilidad del patrimonio moderno y de los espacios culturales en los centros históricos. El proyecto de la sociedad Progetto UNO Srl se paralizó gracias a una carta de la directora de la PaBACC, Maria Grazia Bellissario, en la que se reconocía al edificio como un destacado ejemplo de la tipología del cine italiano, debido a sus atributos arquitectónicos, su diseño, sus soluciones espaciales y estructurales, su mobiliario y decoración interior. Además, se solicitó con carácter 
Durante una inesperada visita del Ministro de Cultura, Dario Franceschini, al América en julio de 2014, en la cual le fueron enseñadas las obras de mantenimiento efectuadas gracias a la autofinanciación (figura 7), el funcionario declaró que ambas nominaciones estaban a punto de ser aprobadas para garantizar la continuidad del lugar como cine. También señaló que el propietario del momento podía acogerse al recién aprobado "Decreto Cultura", pues este contempla la financiación de hasta un $30 \%$ de la restauración y actualización de las salas cinematográficas construidas y en funcionamiento antes de 1980.

urgente adoptar las medidas necesarias destinadas a su protección y valorización.

Para completar la candidatura del Cinema y para activar aún más el debate, durante junio del 2014 se presentó al Ministerio de Cultura otra solicitud de Bien de Interés Cultural por los mosaicos del interior del edificio, realizados por el reconocido escultor Pietro Cascella (Pescara, 1921 - Pietrasanta, 2008) junto a su mujer, la pintora y escultora Annamaria Cesarinni Sforza.

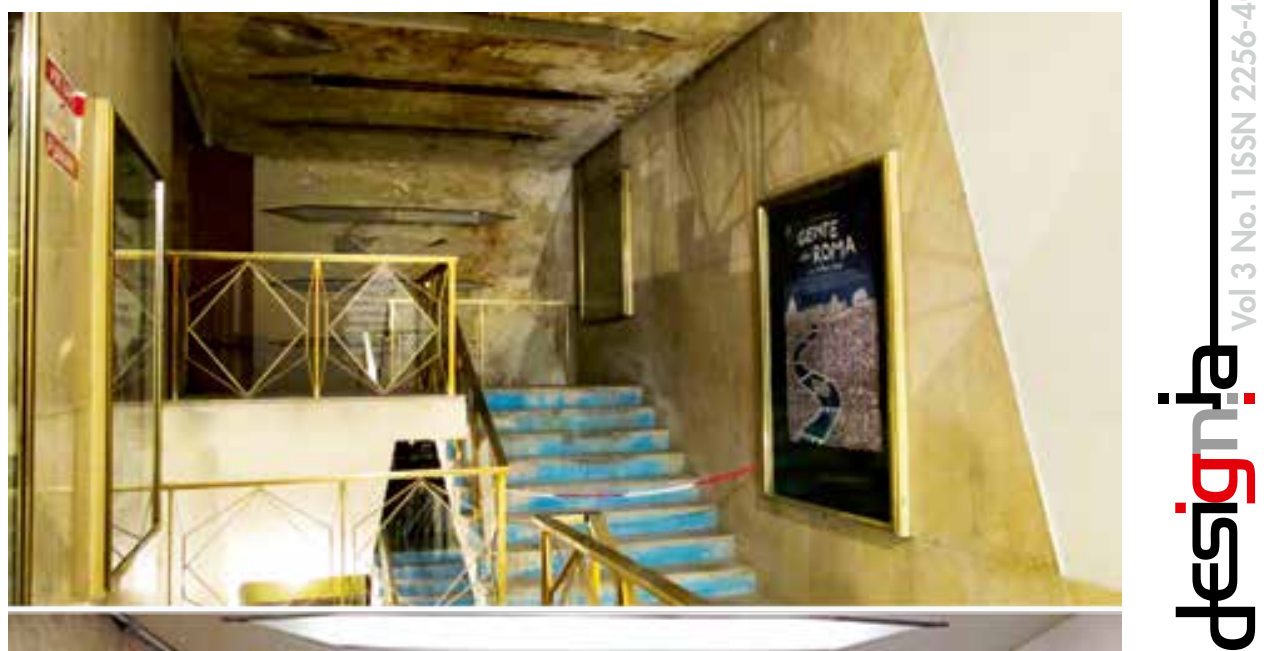

Figura 7. Resultado de las obras de mantenimiento (antes y después) Fuente: la autora 
Pocas semanas después, el propietario presentó un recurso en que apeló al derecho de propiedad privada. La sala, ocupada por estudiantes universitarios de entre 16 y 21 años, fue pacíficamente desalojada por las fuerzas del orden. Pero la experiencia no murió en ese momento, gracias a la incondicional vocación civil de los jóvenes, quienes trasladaron la actividad cultural a las calles y plazas de Roma. De tal modo, crearon una mágica simbiosis entre los romanos y el mundo del cine y la cultura. Incluso el Presidente de la República escribió personalmente una carta al movimiento en la cual consideró como una acción positiva el hecho de que en nombre de la historia y la cinematografía existieran personas entregadas a la salvaguarda de teatros, espacios culturales y cinematográficos en el centro histórico de la ciudad. La consecuencia inmediata fue la inscripción del Cinema, el 28 de noviembre de 2014, en la lista del Patrimonio Cultural del país, dado su valor histórico, artístico y arquitectónico. Además, se le dio el nivel de protección máxima.
No ha sido fácil llegar a este punto. Aunque las intenciones son buenas y el patrimonio moderno "está de moda" entre las instituciones y los colectivos de arquitectos, las acciones reales siguen reservadas a un círculo muy pequeño, la normativa todavía permanece muy centrada en el concepto de "monumento" y se da poco espacio para una amplia participación popular. Los procesos no son claros ni directos y la propiedad privada no se compromete con determinación.

El Cinema América ha establecido un precedente en el modo de "hacer cultura". Simboliza el inicio de un cambio de sensibilización surgido desde abajo, comprometido con la cultura, que servirá como modelo para experiencias similares en ciudades donde el Patrimonio Moderno cumple un rol fundamental.

\section{REFERENCIAS BIBLIOGRÁFICAS}

Intrieri, M. R. (2004). Itinerari Romani 2. Le sale cinematografiche tra Ricordo e Attualità. Roma: Prospettive, Ordine degli Architetti di Roma e Provincia.

Jokilehto, J. (2003). Continuity and change in recent heritage. World Heritage papers 5: Identification and documentation of modern heritage. Paris: Unesco.

Piacentini, M. (1918). II Nuovo Corso "Cinema Teatro" in Piazza San Lorenzo in Lucina in Roma. Architettura Italiana, 13, (5).

\section{BIBLIOGRAFÍA COMPLEMENTARIA}

Caccia, S. (2007). Luoghi e architetture del cinema in Italia. Pisa: ETS.

Carughi, U. (2012). Maledetti i vincoli. La tutela dell'architettura contemporanea. Roma: Allemandi. 
De Carlo, L. \& Albisini, P. (1989). I luoghi della rappresentazione cinematografica. Per una ipotesi di schedatura delle sale cinematografiche a Roma. Romacentro, (10).

Diniz Moreira, F. (2012). Os desafios postos pela conservação da arquitetura moderna. CPC, (11), 152-187.

DOCOMOMO Italia (2008). Notizie dal moderno: Appello per il Cinema Amerina in Trastevere a Roma. Recuperado el 1 de febrero de 2014, de www. docomomoitalia.it

Finelli, L. \& Foa, F. (2000). Angelo di Castro. Architetto Romano. Roma: Kappa.

International Council on Monuments and Sites. (2011). Approaches for the conservation of twentieth-century architectural heritage. Recuperado el 5 de febrero de 2014, de www.icomos-isc20c.org

Lavini, C. (1918). II Cinematografo. Architettura Italiana, 13, (9).

Macdonald, S. (2013). Modern matters: Breaking the barriers to conserving Modern Architecture. Recuperado el 8 de marzo de 2014, de www.getty.edu

Mariano, F. (1983). Angelo di Castro, disegni, pitture, architetture: escritos de Filiberto Menna, Paolo Portoghesi, Ludovico Quaroni. Roma: Kappa.

Muratore, G. \& Veneziani, R. (1982). I Cinema nella Città, catalogo della mostra documentaria sulla sale cinematografiche di Roma. Roma: Istituto per l'Architettura Contemporanea.

Zevi, L. (2013). I/ nuovissimo manuale dell'architetto. Roma: Mancuso. 